\title{
AS ATIVIDADES ACADÊMICAS CURRICULARES COMPLEMENTARES E O PROCESSO FORMATIVO DO PROFISSIONAL DE EDUCAÇÃO FÍSICA: UM ESTUDO NAS IES PÚBLICAS DE MINAS GERAIS
}

\author{
Marcia Helena Resende \\ Universidade Federal do Triângulo Mineiro, Uberaba, Minas Gerais, Brasil \\ Vilma Lení Nista-Piccolo \\ Universidade de Sorocaba, Sorocaba, São Paulo, Brasil
}

\begin{abstract}
Resumo
Esta pesquisa voltou-se ao clareamento das Atividades Acadêmicas Curriculares Complementares (AACC) nas IES públicas de Minas Gerais, como uma das essências pedagógicas da e para a formação docente, a partir da interpretação do Projeto Político Pedagógico destas instituições. Optou-se por uma investigação qualitativa com enfoque descritivo. Para a análise dos dados, foram estabelecidas categorias, e estas apresentadas por meio de quadros explicativos. Os resultados obtidos declaram que todas as IES cumprem a carga horária destinada às AACC. Nenhuma das instituições analisadas aponta momentos para discussão ou devolução dos relatórios referentes às AACC. Todas as IES se preocupam em oferecer aos ingressantes ensino de qualidade, fomentando pesquisas e publicações.
\end{abstract}

Palavras-chave: Formação docente. Formação docente em Educação Física. Projeto Pedagógico. AACC.

\section{Introdução}

Questões sobre a qualidade do sistema educacional em nosso país e os aspectos que envolvem a formação docente (com o foco voltado para a busca de um docente crítico, engajado, comprometido, reflexivo, que atenda às expectativas pedagógicas) fazem parte de debates e reflexões de vários segmentos sociais, na tentativa de encontrar (novas) propostas e/ou oferecer sugestões que almejam a melhora efetiva da atuação docente. Um dos aspectos levantados ultimamente, como ponto-chave, é a aquisição de competências e habilidades por parte desse profissional que o capacitem a promover significativas mudanças na sua prática pedagógica.

O sentido de competência a que nos referimos é aquele empregado por Perrenoud (2000), que a entende como a capacidade do indivíduo de agir eficazmente em determinada situação, tendo como base os conhecimentos adquiridos, sem, contudo, limitar-se a eles. $\mathrm{Ou}$ 
seja, é a capacidade de mobilizar informações, recursos cognitivos e habilidades para resolver com eficácia uma determinada situação.

Pensar a formação de professores implica o entendimento de uma sociedade em seu sentido multicultural (diferente de enxergá-la numa perspectiva monocultural); uma sociedade composta por seres humanos heterogêneos e homogêneos ao tempo e ao espaço onde vivem. Heterogêneos, quando se evidenciam os aspectos culturais, étnicos e linguísticos, e que, como tal, o ser humano precisa ser respeitado e valorizado e não discriminado ou silenciado. E homogêneos, quando seus esforços convergem para uma busca de conhecimentos.

A qualidade da formação docente vem apontando para que se assegure ao alunoprofessor a aquisição e o desenvolvimento de habilidades e atitudes que lhe possibilitem dialogar, adaptar e intervir em uma realidade educativa adversa, mediante a apreensão de competências intelectuais, pedagógicas, técnicas e políticas.

Tendo em vista a preocupação constante com a formação docente e sua notória relação de dependência aos programas formadores desse profissional, Libâneo (2002) escreve que o ponto principal para se formar um professor está no currículo e nos seus métodos, nos quais os processos de aprendizagem e os resultados esperados dos alunos são os mesmos conteúdos trabalhados pelos professores em sua formação.

$\mathrm{O}$ entrelaçamento dos saberes, oriundos das próprias experiências dos docentes em sua trajetória como alunos, dos processos de formação e de suas práticas cotidianas é essencial na formação do professor, uma vez que "há um reconhecimento de que para saber ensinar não basta a experiência e os conhecimentos específicos, mas se fazem necessários os saberes pedagógicos e didáticos" (PIMENTA, 2005, p. 25).

Sobre esses cursos formadores de professores, Souza (2007, p. 13) diz que eles “[...] deveriam instrumentalizar de forma mais reflexiva e competente os formandos para que os mesmos possam atuar e organizar melhor as situações de aprendizagens dentro do contexto escolar para o qual se qualificaram".

Reforçando a importância da universidade no processo de formação do professor/ pesquisador, Pimenta e Anastasiou (2002, p. 45) nos apontam que:

A sólida formação [...] só pode ser desenvolvida por universidades compromissadas com a formação e o desenvolvimento de professores capazes de aliar a pesquisa nos processos formativos. Estamos, portanto, falando de um processo emancipatório, compromissado com a responsabilidade de tornar a escola parceira na democratização social, econômica, tecnológica e cultural, que seja mais justa e igualitária.

Como o profissional de Educação Física também atua na educação escolar, há necessidade de se refletir sobre a importância da formação inicial e do currículo no curso de licenciatura deste profissional.

A Educação Física, no Brasil, passa, no momento, por transformações necessárias, e muitas produções científicas têm se ocupado em discutir essas mudanças. De certo modo, isso tem gerado preocupação em relação à formação do profissional dessa área, pois é preciso que ele seja adequadamente qualificado e adquira conhecimento suficiente para atender às situações-problema a serem enfrentadas no mercado de trabalho, ou seja, que sua futura atuação seja adequada à demanda exigida pela sociedade.

A formação recebida mostra-se incipiente, por exemplo, quando o aluno, futuro professor, não consegue transformar, no momento da sua atuação no ambiente escolar, o saber teorizado adquirido em sala de aula em prática aplicada; quando ele não consegue resolver uma situação pertinente ao contexto em que atua, pois não consegue adaptar os saberes adquiridos ao conhecimento necessário para ampará-lo nessa circunstância; quando apresenta e discute teorias e não consegue associá-las à prática aplicada. 
Como as características dos ambientes onde os futuros professores de EF irão atuar apresentam peculiaridades que lhes são próprias, eles precisam estar aptos a realizar essa transferência de conhecimentos, da teoria para a prática, e a administrar as diferenças presentes nos grupos de alunos recebidos.

Um dos elementos que compõe as exigências na formação de um professor, e que merece uma atenção especial nos currículos dos cursos de licenciatura, são as Atividades Acadêmicas Curriculares Complementares. Assim como os estágios, elas são atividades que podem contribuir de forma significativa para a formação docente, quando realizadas de forma reflexiva. De acordo com o alerta de Pimenta e Lima (2004, p. 67), elas não devem promover "a prática pela prática e o emprego de técnicas sem a devida reflexão", tendo em vista que isso poderia reforçar "a ilusão de que há uma prática sem teoria".

Ampliar as possibilidades de experiências práticas durante o curso superior, por meio das AACC, tem sido necessário, uma vez que são alternativas que contribuem para o processo formativo, possibilitando ao profissional a aquisição de conhecimentos significativos que facilitam sua atuação.

Podemos dizer que, mesmo após as mudanças curriculares e as transformações nos princípios pedagógicos que ocorreram nas diretrizes de um curso de EF em nosso país, ainda temos estagiários que adentram o universo escolar com insegurança.

Como as IES têm atendido às necessidades do aluno-professor no que se refere aos aspectos pedagógicos de sua formação, especificamente no tocante às Atividades Acadêmicas Científicas Culturais (AACC)?

Daí nosso olhar se dirigiu para a análise das matrizes curriculares que formam professores de EF nas IES públicas do estado de Minas Gerais, atentando-nos para este aspecto pedagógico, uma vez que a estrutura adotada pela instituição formadora pode refletir diretamente na sua profissionalização e na (re)construção de seus conhecimentos diante de uma instituição social tão importante como a escola de ensino formal.

Coadunamos com o pensamento de Darido (2001), ao escrever que, apesar de todas as mudanças ocorridas na área de EF, como aumento da quantidade de livros publicados, criação de novas revistas, ampliação de pesquisas científicas específicas da área, a valorização da prática pedagógica ainda permanece no "discurso", uma vez que todos esses procedimentos apontados não promoveram nem influenciaram efetivamente a prática pedagógica.

\section{Procedimentos metodológicos}

Por meio de uma abordagem qualitativa descrita, esta pesquisa analisou os Projetos Políticos Pedagógicos (PPP) dos cursos de Licenciatura em EF das IES públicas do estado de MG, a fim de identificar as possíveis convergências e divergências existentes entre essas instituições. Para isso, interpretaram-se as matrizes curriculares desses cursos, abordando a definição dada, em cada uma delas, para os aspectos pedagógicos que envolvem a formação docente no que tange às AACC.

A escolha do estado de Minas Gerais se deveu ao fato de ser ele o segundo estado brasileiro com maior número de oferta de cursos de licenciatura em $\mathrm{EF}$ em todo o país. Optou-se pelas IES públicas por elas se constituírem num importante espaço para produção e disseminação de novos saberes, por contarem com alunos assessorados por pesquisas desenvolvidas pelos docentes e por oferecem os cursos mais concorridos.

O método utilizado para coleta de informações foi a análise documental proposta por Laville e Dionne (1999), investigando as Matrizes Curriculares desses cursos.

Das 98 IES do estado de Minas Gerais que oferecem curso de EF (cadastradas no MEC e disponibilizadas em seu respectivo site), 86 delas licenciam o professor que vai atuar em 
escolas de Ensino Básico. Desse total, somente 12 IES são públicas, sendo duas dessas IES com seus campi em diferentes cidades do mesmo estado, no entanto com o mesmo PPP.

De todas as IES pesquisadas, apenas uma não disponibilizou o PPP e os documentos necessários à pesquisa. Embora as pesquisadoras tivessem tentado vários contatos com a coordenadora do curso, via e-mail e telefone, não obtendo êxito.

Para a análise das informações coletadas, optou-se pelo estabelecimento de categorias proposto por Marconi e Lakatos (1999). Em seguida, houve a elaboração de um quadro, observando as categorias apontadas, e o critério de ordem para as IES foi definido por meio de um sorteio.

Estabeleceram-se códigos para cada uma dessas instituições de ensino, utilizando números e siglas, sem identificação das IES.

\section{Interpretação dos dados}

O quadro 1 mostrado corresponde à categoria AACC, no qual apresentamos as unidades elencadas a partir da análise dos PPP de cada IES.

Quadro 1: Unidades elencadas a partir da análise dos PPP de cada IES.

\begin{tabular}{|c|c|c|c|c|c|c|c|c|c|c|}
\hline CATEGORIA AACC & $\begin{array}{c}\text { IES } \\
1\end{array}$ & $\begin{array}{c}\text { IES } \\
2\end{array}$ & $\begin{array}{l}\text { IES } \\
3\end{array}$ & $\begin{array}{l}\text { IES } \\
4\end{array}$ & $\begin{array}{l}\text { IES } \\
5\end{array}$ & $\begin{array}{l}\text { IES } \\
6\end{array}$ & IES & $\begin{array}{l}\text { IES } \\
8\end{array}$ & $\begin{array}{l}\text { IES } \\
9\end{array}$ & $\begin{array}{l}\text { IES } \\
10\end{array}$ \\
\hline $\begin{array}{l}\text { Participação em projetos (PIBID } \\
\text { PRODOCENCIA, SEGUNDO } \\
\text { TEMPO, PROETI, MAIS } \\
\text { EDUCAÇÃO) }\end{array}$ & $\mathrm{X}$ & & $\mathrm{X}$ & & & & & & & \\
\hline $\begin{array}{l}\text { Organização e arbitragem de } \\
\text { eventos esportivos }\end{array}$ & $X$ & & $\mathrm{X}$ & & & & & & $X$ & $X$ \\
\hline $\begin{array}{l}\text { Participação em órgãos } \\
\text { colegiados, de representação } \\
\text { estudantil e atividades autorizadas } \\
\text { pelo colegiado }\end{array}$ & & $\mathrm{X}$ & & & & $X$ & $\mathrm{X}$ & & & $\mathrm{X}$ \\
\hline $\begin{array}{l}\text { Discussões temáticas voltadas à } \\
\text { prática docente }\end{array}$ & & $X$ & & & $X$ & & & & & \\
\hline $\begin{array}{l}\text { Participação em projetos de } \\
\text { iniciação à pesquisa }\end{array}$ & $X$ & $X$ & $X$ & $X$ & $X$ & $X$ & $X$ & $X$ & $X$ & $X$ \\
\hline $\begin{array}{l}\text { Participação em atividades de } \\
\text { aperfeiçoamento e enriquecimento } \\
\text { cultural }\end{array}$ & & & $X$ & & & & $X$ & $X$ & $X$ & $X$ \\
\hline $\begin{array}{l}\text { Realização de estágios } \\
\text { extracurriculares }\end{array}$ & & & & $X$ & & & $X$ & & & \\
\hline $\begin{array}{l}\text { Participação em eventos } \\
\text { (simpósios, seminários, fóruns, } \\
\text { palestras, conferências) }\end{array}$ & $X$ & $X$ & $X$ & $X$ & $X$ & $X$ & $X$ & $X$ & $X$ & $X$ \\
\hline
\end{tabular}

Fonte: PPP das instituições

Nota: Elaborado pelas autoras (2016). 
Ao analisarmos as IES públicas de $\mathrm{MG}$, pudemos perceber que todas cumprem a Resolução CNE/CP 02/2002, ao ofertar as AACC ao longo do curso, com uma carga horária de 200 horas. Entretanto, conforme análise dos PPP das IES, enquanto algumas proporcionam uma orientação quanto à forma de realizar as AACC, muitas vezes não cabendo ao alunoprofessor a eleição dessas atividades, outras determinam que elas têm de ser referendadas pelo colegiado do curso. O que corrobora a ideia de Kasseboehmer e Ferreira (2010, p.6), ao apontarem que:

apesar da [...] flexibilização curricular e a consideração dos interesses e da opinião dos graduandos, a escolha em relação às atividades a serem realizadas não podem pautar-se, exclusivamente, nas decisões tomadas pelo estudante. Mesmo que este seja um aluno comprometido com sua formação, ele não possui maturidade suficiente para reconhecer qual atividade melhor contribuirá para o seu desenvolvimento, especialmente se os objetivos das AACC não forem devidamente discutidos com ele.

Em todas as instituições pesquisadas, destaca-se a "participação em congressos, simpósios, palestras, seminários", como atividades construtivas, pois, como afirma Schön (2000), na formação do professor reflexivo, as experiências vividas em atividades diferentes do currículo normativo são muito enriquecedoras e dão cabedal para solucionar situaçõesproblema com os quais, porventura, ele possa se confrontar. Além de possibilitar ao alunoprofessor uma reflexão sobre a área em que atua, permite "um avanço nos conhecimentos específicos", conforme nos aponta Nista-Piccolo (2010).

Quando o aluno-professor tem a oportunidade de vivenciar essas atividades, ele consegue ampliar seus conhecimentos em virtude das trocas de informações/experiências, da reflexão desencadeada por reunião de profissionais, pelo contato com outros estudantes de uma determinada especialidade ou que comungam interesses comuns. Os trabalhos apresentados e as palestras proferidas podem refletir os avanços e a difusão do conhecimento científico. Cabe ao aluno-professor compreender que os conhecimentos adquiridos durante seu processo formativo não podem nem devem ficar restritos à sala de aula. A sua participação nessas atividades se torna essencial e enriquecedora, pois alarga sua maneira de ver o mundo e constitui um diferencial na sua formação acadêmica e na futura docência.

A categoria "Participação em projetos de iniciação à pesquisa" foi elencada por todas as instituições pesquisadas, o que demonstra que todas seguem o que dispõem o Parecer CNE/CP 009/2001 e a Resolução CNE/CP 01/2002; 02/2002 e 07/2004. Esse fato faz supor que todas as instituições estudadas preocupam-se em oferecer aos seus alunos - ingressantes mediante seleção prévia, por meio de vestibular - um ensino de qualidade, pautado nas exigências legais, que responde à necessidade sempre crescente de fomentar suas pesquisas e gerar publicações.

Segundo nos adverte Lovisolo (2003), a produção científica não pode representar apenas uma obrigação a cumprir - elaborar uma monografia, produzir um artigo ou realizar apresentação em eventos científicos - mas, sim, se configurar como uma possibilidade de formação e valorização da cultura científica. A participação em projetos de iniciação científica deve ir além dos "muros da Universidade", numa ação conjunta em que "haja uma interação entre a pesquisa e o ensino, de modo que os conhecimentos obtidos pela pesquisa possam ser incorporados ao ensino" (FORMOSINHO, 2011, p.143).

A pesquisa científica é essencial na vida acadêmica, tanto no sentido de obter e divulgar conhecimento como para propiciar ao aluno-professor competência para pesquisar sua própria atuação. Nessa perspectiva, Demo (2000, p.22) aponta que: "Educar pela pesquisa tem como condição essencial primeira que o profissional da educação seja pesquisador, ou 
seja, maneje a pesquisa como princípio científico e educativo e a tenha como atitude cotidiana". E complementa, em outro texto, afirmando: "Não se atribui a função de professor a alguém que não é basicamente pesquisador" (DEMO, 1991, p.15)

Corroboram essa ideia Netto e Rocha (2003, p. 25), ao escreverem que: "A experiência da iniciação científica produz efeitos marcantes na formação dos estudantes envolvidos. Aqueles que despertam para a vocação científica encontram abertas as portas da pósgraduação e trilham a caminhada com competência e certa tranquilidade".

Observamos que as IES 4 e 7 validam as atividades que são "desenvolvidas por meio de estágios extracurriculares" como AACC, desrespeitando a legislação da licenciatura que deixa claro que as AACC não podem ser confundidas com atividades que se realizam como Estágio Supervisionado (Resoluções CNE/CP 01/2002; 02/2002 e 07/2004).

No caso das IES apontadas no quadro, o PPP do curso não deixa claro o que seria esse "estágio extracurricular", não identificando quais atividades seriam computadas nem a carga horária delas.

Fica, então, a nossa preocupação quanto à realização das AACC por meio de estágios extracurriculares, como mão de obra barata em eventos e/ou em atividades ligadas à área por serem economicamente mais viáveis para as instituições solicitantes. É preciso valorizar as atividades propostas e realizadas por esse aluno-professor e entender que elas devem realmente contribuir com e para sua formação e não se configurar apenas como uma atividade barata para o mercado. Desse modo, esse quesito precisa ser levado em consideração pelas IES citadas.

$\mathrm{Na}$ categoria "Participação em atividades de aperfeiçoamento e enriquecimento cultural", percebemos que a maioria das IES pesquisadas atende ao pressuposto básico dessas atividades culturais, ou seja, as AACC devem contribuir para ampliar o universo cultural dos alunos, visando à formação de profissionais mais reflexivos, criativos e sensíveis.

De acordo com Paquay et al. (2001), além dos conhecimentos culturais da atualidade, é preciso conceber um conjunto de competências que o profissional reflexivo deve dominar. Os responsáveis pelo processo formativo têm de levar em conta os conhecimentos adquiridos em diferentes atividades realizadas fora de sala de aula, já que eles podem fundamentar a solução de situações-problema. A importância da formação cultural também é ressaltada em estudo realizado por Kasseboehmer e Ferreira (2010, p.22), que consideram que "as atividades culturais precisam ser abordadas na formação de professores tendo como objetivo propiciar a compreensão de diferentes produções e discutir as repercussões e influências das diferentes culturas sobre as pessoas e a sociedade".

Apenas duas IES ( 2 e 5 ) apresentaram a categoria "Discussões temáticas voltadas à prática docente", o que nos surpreendeu, uma vez que, conforme nos aponta Tardiff (2002), a possibilidade de socialização das experiências vividas pelos graduandos, por meio de debates e discussões com mediação do professor, leva os alunos a relacionar esses conhecimentos com a ação profissional futura, identificando seu significado e utilidade.

A ausência de discussões e debates nos permite inferir que os relatórios e documentos apresentados pelo aluno-professor, quando do cumprimento das AACC, são vistos de forma burocrática, apenas como meio de efetivação das normas legais, quando se limita a formação docente aos conhecimentos adquiridos em sala de aula. Não lhe é concedida a oportunidade de alargar sua visão de mundo de modo crítico e reflexivo, conforme nos alertam Tardiff (2002) e Alarcão (2001).

Perrenoud (2000) corrobora essa ideia, ao afirmar que a ausência de momentos de discussões faz com que o processo de formação desconsidere a importância do desenvolvimento da postura crítica e reflexiva dos discentes para o aprofundamento, a análise e o estabelecimento de relações de uma diversidade de saberes provenientes de atividades realizadas fora do contexto universitário. Paquay et al. (2001) também reafirmam essa visão, 
ao apontar que, quando as IES promovem esses momentos, fica explícita a importância que é dada ao contato dos discentes com a diversidade de conhecimentos aplicados em outros contextos e que podem contribuir para a ampliação de seu repertório de saberes.

Em relação à "Organização e arbitragem de eventos esportivos", percebemos que $40 \%$ das IES pesquisadas aceitam essa categoria como atividades que podem contribuir para o enriquecimento cultural, profissional e pessoal do aluno-professor, ou seja, como forma de cumprimento das AACC, conforme dispõe o Parecer CNE/CP 009/2002, ao idealizar que, tendo em vista a formação em Licenciatura, as AACC têm por finalidade ampliar os conhecimentos em diferentes âmbitos (pessoal, acadêmico, cultural e atuação profissional).

As IES 1 e 3 apontam a categoria "Participação em projetos (PIBID, PRODOCENCIA, SEGUNDO TEMPO, PROETI, MAIS EDUCAÇÃO)" como atividade que enriquece a formação do aluno-professor, pois, ao participar desses projetos, ele amplia sua visão de mundo, ao se defrontar com realidades que circundam o ambiente escolar; conhece as ações pedagógicas ali realizadas; interage com o processo de ensino e aprendizagem de diferentes contextos sociais; tem a oportunidade de pôr em prática as atividades aprendidas na Universidade; contribui para o estreitamento entre Universidade e escola, e conhece as políticas públicas voltadas para a docência.

Além disso, a participação nesses projetos pode contribuir para minimizar um dos problemas relacionados à formação docente, que é a dicotomia entre teoria e prática. Corroborando a ideia, Kimura (2008, p.16) escreve que é do contexto social:

que surge a condição de sujeitos reais, como são realmente os alunos e professores, os principais frequentadores da escola. As características desse contexto, de uma ou outra maneira, em seu estado puro ou transformadas, em sua concretude ou em suas reverberações, ajudam a compor as condições integrantes do universo escolar.

Ao elencar a categoria relacionada às AACC quanto à participação do aluno-professor em "órgãos colegiados, de representação estudantil e atividades autorizadas pelo colegiado", observamos que essa categoria se encontra presente somente nas IES 2, 6, 7 e 10. Entendemos que esses espaços se constituem em locais que possibilitam ao aluno-professor o exercício da cidadania, ao contribuir para que eles assumam uma postura crítica e ativa ao lutar por seus interesses e por uma educação de qualidade.

Essa participação também possibilita o surgimento de lideranças que defendam os interesses democráticos e a construção de valores éticos e morais desejáveis na nossa sociedade. As relações aí estabelecidas se concretizam em um meio marcado por diferentes tendências políticas e ideológicas, e o diálogo, a discussão e a reflexão constantes permitiriam ao aluno-professor vivências e conhecimentos relacionados aos direitos, deveres inerentes à profissão, contribuindo, dessa forma, para uma formação mais crítica e participativa em que o aluno-professor se torne condutor e sujeito da sua própria história.

Reafirmando a ideia, Fávero (2006, p. 19) escreve que a universidade "deve ser o espaço em que se desenvolve um pensamento teórico-crítico das ideias, opiniões, posicionamentos, como também o encaminhamento de propostas e alternativas para a solução dos problemas. Não restam dúvidas de que essas tarefas constituem um aprendizado difícil e por vezes exaustivo, mas necessário".

\section{Considerações finais}

Procuramos nesta pesquisa investigar como as Atividades Acadêmicas Científicas Culturais ocorrem nas Instituições de Ensino Superior públicas em Minas Gerais por meio da leitura do Projeto Político Pedagógico das instituições. 
Os resultados encontrados, após o levantamento das categorias, nos permitiu apontar que todas as instituições cumprem a Resolução CNE/CP 02/2002, no que tange ao cumprimento de carga horária e na sua distribuição ao longo do curso. Algumas instituições proporcionam uma orientação quanto à forma de realizar as AACC, muitas vezes não cabendo ao aluno-professor a eleição dessas atividades. Em outras instituições, estas devem ser referendadas pelo colegiado do curso. Ao nosso ver, isso deveria ocorrer de forma construtiva, após momentos de discussão e debates, em que o próprio aluno, consciente da necessidade e importância destas para sua formação profissional, pudesse elencar as atividades que podem contribuir para sua atuação.

Todas as instituições apontam a importância da participação do aluno-professor em eventos diversos (congresso científico, palestras, simpósios, fóruns, conferências) e em projetos de iniciação à pesquisa científica. Entendemos que tão importantes quanto a participação nessas atividades são os momentos para troca de experiências com outros acadêmicos e profissionais da área, numa busca constante pelo conhecimento e pelo retorno das pesquisas ao seu local de origem, para que elas possam promover as mudanças que aí se fizerem ou se fazem necessárias.

Um dos aspectos que mais nos chamou a atenção, dentre as categorias elencadas, foi a ausência de momentos para discussão temática voltada à prática docente, na maioria das instituições pesquisadas. Entendemos que esses momentos são de extrema relevância no processo formativo, uma vez que permitem ao aluno-professor avançar em relação aos conhecimentos, ampliar seu processo formativo, possibilitando maior articulação entre o discurso e a prática pedagógica. E que as AACC não sejam vistas como e tão somente cumprimento legal das normas, de forma burocrática.

Este é um fator que precisa ser discutido com mais intensidade pela área acadêmica, responsável pela formação do professor de Educação Física, no e com o intuito de melhor subsidiá-lo para o exercício da docência.

Sem dúvida nenhuma, a obrigatoriedade legal da inserção das AACC nos currículos se constitui uma inovação promissora, pois oferece uma importante contribuição para reduzir a lacuna ainda existente entre a formação profissional no Ensino Superior e a aplicação das experiências realizadas fora do ambiente institucional.

As AACCs podem contribuir de forma significativa para minimizar alguns dos problemas relacionados à dicotomia entre teoria e prática, quando bem orientadas, quando são percebidas pelo aluno-professor como meio de melhorar a sua qualificação no enfrentamento de situações-problema advindos do ambiente escolar.

Entendemos também que, ao analisarmos somente os documentos fornecidos pelas instituições, tal fato limitou nossa pesquisa, uma vez que não nos permitiu apontar com clareza o como e o quanto as AACC, contempladas nos PPP como proposta, são desenvolvidas de modo eficaz na formação dos futuros professores. Assim, não é possível saber se o que se propõe se cumpre. Seria necessário, em paralelo a esse estudo, uma investigação in loco, analisando como essas atividades estão sendo desenvolvidas nessas instituições. 


\title{
THE COMPLEMENTARY CURRICULAR ACADEMIC ACTIVITIES AND THE FORMATIVE PROCESS OF THE PHYSICAL EDUCATION PROFESSIONAL: A STUDY IN PUBLIC IES OF MINAS GERAIS
}

\begin{abstract}
This research turned to bleaching clear out the Complementary Curricular Academic Activities (AACC) in public IES of Minas Gerais, as one of the pedagogical essences of and teacher training, from the interpretation of the Pedagogic Political Project of these institutions. We chose a qualitative research with descriptive approach. For data analysis, categories were established and these werw presented through explanatory tables. The results obtained state that all the IES meet the workload designed for the AACC. None of the institutions analyzed points moments for discussion or return of AACC reports. All IES are concerned with offering quality education to students, promoting research and publications.

Keywords: Teacher Training. Teacher Training in Physical Education. Pedagogical Project. AACC.

\section{EL PLAN CURRICULAR COMPLEMENTAR Y EL PROCESO FORMATIVO DEL PROFESIONAL DE EDUCACIÓN FÍSICA: UN ESTUDIO EN LAS IES PÚBLICAS DE MINAS GERAIS}

\section{Resumen}

Esta investigación se direccionó a la clarificación de las Actividades Curriculares Complementares (AACC) en las IES públicas de Minas Gerais, como una de las constituyentes pedagógicas de la y para la formación del profesorado, a partir de la interpretación del Proyecto Político Pedagógico de esas instituciones. Se optó por una investigación cualitativa con direccionamiento descriptivo. Para el análisis de los datos se establecieron categorías de análisis presentadas a través de cuadros explicativos. Los resultados obtenidos indican que todas las IES cumplen la carga horaria destinada a las AACC. Ninguna de las instituciones analizadas demuestra momentos de debate o devolución de los informes relacionados a la AACC. Todos los IES tienen la preocupación de ofrecer enseñanza de calidad a los estudiantes, fomentando investigación y publicaciones.

Palabras clave: Formación del Profesorado. Formación del Profesorado de Educación Física. Proyecto Pedagógico. AACC.

\section{Referências}

ALARCÃO, I. (Org.). Escola reflexiva e nova racionalidade. Porto Alegre: Artes Médicas, 2001.

BRASIL. Ministério da Educação. Conselho Nacional de Educação. Resolução CES 58/2004, de 31 de março de 2004. Dispõe sobre as Diretrizes Curriculares Nacionais para os cursos de graduação em Educação Física. Disponível em: <http://www.cref6.org.br/arquivos/leg16.pdf>. Acesso em: 4 ago. 2014.

BRASIL. Ministério da Educação e Cultura. Conselho Nacional de Educação. Parecer no 9/2001, de 8 de maio de 2001. Diretrizes Curriculares Nacionais para a Formação de 
professores da Educação Básica, em nível superior, curso de licenciatura, de graduação plena. Disponível em: <http://portal.mec.gov.br/>. Acesso em: 19 out. 2013.

BRASIL. Ministério da Educação. Conselho Nacional de Educação. Resolução CNE/CP no 02/2002. Institui a duração e a carga horária dos cursos de Licenciatura de Graduação Plena, de Formação de Professores de Educação Básica em Nível Superior. Brasília DF 2002. p. 9.

DARIDO, S. C. Os conteúdos da Educação Física escolar: influências, tendências dificuldades e possibilidades. Perspectivas em Educação Física Escolar. Niterói, v. 2, n. 1, p. 5-25, 2001.

DEMO, P. Educar pela pesquisa. 4 ed. São Paulo: Autores Associados, 2000.

.Professor e seu direito de estudar. In: SHIGUNOV NETO, A.; MACIEL, L.S.B. (Org.). Reflexões sobre a formação de professores. Campinas: Papirus, 2002. p.71-88.

Pesquisa: princípio científico e educativo. 2. ed. São Paulo: Cortez, 1991.

FAVERO, M. de L. de A. A Universidade no Brasil: das origens à reforma universitária de 1968. Revista Educar, Curitiba, n. 28, p.17-36, 2006.

FORMOSINHO, J. Dilemas e tensões da atuação da universidade frente à formação de profissionais de desenvolvimento humano. In: PIMENTA, S. G.; ALMEIDA, M. I. de (Org.). Pedagogia universitária: caminhos para a formação de professores. São Paulo: Cortez, 2011.

KASSEBOEHMER, A. C.; FERREIRA, L.H. Formação cultural do professor de química: as atividades acadêmico-científico-culturais nas universidades públicas do estado de São Paulo. 2010. Disponível em: <http://www.fae.ufmg.br/abrapec/viempec/CR2/p90.pdf>. Acesso em: 4 ago. 2014.

KIMURA, S. Geografia no ensino básico: questões e propostas. São Paulo: Contexto, 2008.

LAVILLE, C.; DIONNE, J. A construção do saber: manual de metodologia da pesquisa em ciências humanas. Porto Alegre: Artes Médicas, 1999.

LIBÂNEO, J.C. Reflexividade e formação de professores: outra oscilação do pensamento pedagógico brasileiro? In: PIMENTA, S.G.; GHEDIN, E. (Org.). Professor reflexivo no Brasil: gênese e crítica de um conceito. São Paulo: Cortez, 2002. p. 53-67.

LOVISOLO, H. R. A política de pesquisa e a mediocridade possível. Revista Brasileira de Ciências do Esporte, Campinas, v. 24, n. 2, p. 97-114, jan. 2003.

MARCONI, M.de A.; LAKATOS, E.M.: Técnicas de pesquisa: planejamento e execução de pesquisas, amostragens e técnicas de pesquisas, elaboração, análises e interpretação de dados. São Paulo: Atlas, 1999.

NETTO, C. A.; ROCHA, M. A. (Org.). A iniciação científica na UFRGS: um projeto institucional. Porto Alegre: UFRGS, 2003. 
NISTA-PICCOLO, V. L. Prolegômenos de uma pesquisa sobre o perfil do professor de Educação Física. Revista Brasileira de Docência, Ensino e Pesquisa em Educação Física, v. 2, n. 1. p. 122 , jul. 2010 b.

PAQUAY, L. et al. Formando profissionais: quais estratégias? quais competências? Porto Alegre: Artmed, 2001.

PERRENOUD, F. Construir as competências desde a escola. Porto Alegre: Artes Médicas Sul, 2000.

PIMENTA, S. G. Formação de professores: identidade e saberes da docência. In:

Saberes pedagógicos e atividade docente. São Paulo: Cortez, 2005. 2002. v. 1.

; ANAStASIOU, L. das G. C. Docência no ensino superior. São Paulo: Cortez, ; LIMA, M. do S. L. Estágio e docência. São Paulo: Cortez, 2004. (Coleção Docência em Formação - Saberes Pedagógicos).

SCHÖN, D. Educando o profissional reflexivo: um novo design para o ensino e a aprendizagem. Porto Alegre: Artmed, 2000.

SOUZA, J. P. Formação do profissional de educação física: o caso da Unioeste. 2007. 284 f. Dissertação (Mestrado em Educação Física) - Universidade São Judas Tadeus São Paulo, 2007.

TARDIFF, M. Saberes docentes e formação profissional. 2. ed. Petrópolis: Vozes, 2002.

THOMAZ, J. R.; NELSON, J. K.; SILVERMAN, S. J. Métodos de pesquisa em atividade física. Porto Alegre: Artes Médicas, 2007.

Endereço para correspondência:

marciaomegah@hotmail.com

Marcia Helena Resende

Universidade Federal do Triângulo Mineiro

Av. Getúlio Guaritá, 330 - Nossa Sra. da Abadia

Uberaba - MG

38025-440 